\title{
Chapter 11 \\ Plantwise: A Knowledge and Intelligence Tool for Food Security through Crop Protection
}

\author{
Claire Beverley and Manju Thakur
}

\begin{abstract}
Food security continues to be significantly impacted by a growing world population, changing climate, increasing food prices and environmental burden. One of the key challenges in reducing crop losses due to pests and diseases is timely delivery of appropriate, actionable extension advice to farmers. Information and communication technology (ICT) has the potential to improve services that connect smallholder farmers to new resources and information, helping to build their knowledge and ultimately improve their livelihoods. Such ICT-driven services have seen rapid growth over the past few years, and CABI has been harnessing this technology in several programmes. This chapter provides insight into digital interventions of the global, CABI-led programme, Plantwise, which aims to assist stakeholders in developing countries to improve their plant health systems by strengthening linkages among all actors involved, so that they can prevent and manage pest outbreaks more effectively. An overview of digital interventions piloted and tested under the umbrella of the Plantwise programme is illustrated with selected case studies. Interventions include pest diagnosis and management advice delivered via a website, plant health data collection, using a customized mobile application, and educational simulation games for ongoing support.
\end{abstract}

\footnotetext{
C. Beverley $(\triangle)$

CABI, Wallingford, UK

e-mail: c4beverley@hotmail.co.uk
}

M. Thakur

CABI, New Delhi, India

e-mail:m.thakur@cabi.org 


\section{Background}

Smallholder farmers in developing countries, who produce enough food to feed their families with some surplus to sell at the local market, comprise one of the main groups to be affected by emerging plant pests ${ }^{1}$ and subsequent yield loss. Approximately 500 million smallholder farmers provide over $80 \%$ of the food for a large part of the developing world (International Fund for Agricultural Development 2013). CABI, through its flagship development programme, Plantwise, aims to support relevant United Nations Sustainable Development Goals (SDGs) by improving farmers' yields and incomes, while reducing the use of toxic pesticides through the provision of actionable management advice based on safe principles of integrated pest management (IPM).

Achieving a world without hunger by 2030 depends on increasing the productivity of smallholder farmers; however, their crops face significant threats. Yearly, an estimated $25-40 \%$ of six major crops grown worldwide is lost to pests (Oerke 2006), and yield loss estimates recorded by Savary et al. (2019) suggest the highest losses are associated with food-deficit regions with fast-growing populations, and frequently with emerging or re-emerging pests and diseases. If crop losses were reduced by as little as 1\%, millions more people could be fed (Plantwise 2019). The challenge is to deliver appropriate, actionable extension advice to farmers, at the right time, to help them reduce crop losses.

Plantwise is a global programme led by CABI to help stakeholders in developing countries improve their plant health systems by strengthening linkages between stakeholders, so that they can prevent and manage pest outbreaks more effectively. The focus of Plantwise is to support male and female smallholder farmers in developing countries to lose less of what they grow to pests so that food security is increased, poverty is alleviated and livelihoods are improved. A global network of plant clinics in more than 30 developing and transitional countries across Africa, Asia and the Americas has been established in collaboration with national agricultural advisory services. Plantwise enables farmers to manage pests more effectively by improving the creation, quality and exchange of plant health knowledge.

The plant clinic concept, which is based on the human healthcare system (Bentley 2009), first began in an initiative called the Global Plant Clinic (Boa 2009), and is now promoted through Plantwise. The plant clinics are owned and run by plant health extension staff who have been trained as plant doctors. Plant doctor training, developed by science experts at CABI, comprises two modules covering field diagnostics and plant clinic operation (module 1) and giving good recommendations (module 2). Training is delivered either by CABI staff or by partners within the agricultural advisory services that have taken part in plant doctor training and a subsequent Training of Trainers (TOT) programme. Once training is complete, plant doctors are able to set up demand-driven plant clinics where farmers can seek

\footnotetext{
${ }^{1}$ Definition from IPPC in ISPM5 "Any species, strain or biotype of plant, animal or pathogenic agent injurious to plants or plant products" (FAO 2013).
} 
free, practical and immediate crop management advice. Farmers visit plant health clinics with samples of their affected crops, and plant doctors offer a science-based diagnosis followed by a recommendation of how to manage the current problem and advice on ways to prevent it in the future.

The plant clinic network is reinforced by the Plantwise Knowledge Bank, a gateway to practical, online and offline plant health information, including diagnostic resources and best-practice pest management advice.

\section{Harnessing Innovative Technologies for Information Delivery and Collection}

\section{Online Plantwise Knowledge Bank}

Through the Plantwise programme, CABI has harnessed different information and communication technology (ICT) approaches to reach out to key stakeholders. The first and foremost intervention in this direction was the launch of the Plantwise Knowledge Bank website in 2012. It was recognized early on in the programme that there would be a need for a central information resource for crop protection, the Knowledge Bank, to serve the diverse stakeholders within a national plant health system (Leach and Hobbs 2013).

The Plantwise Knowledge Bank (www.plantwise.org/knowledgebank) is an open-access, online resource that provides plant health information to users, with focus on developing and transitional countries across Africa, Asia and the Americas. Core publishing capabilities of CABI are supplemented with the knowledge, skills and understanding of internationally based science staff and their network of collaborators to deliver science-based information for use in local contexts. The gateway aims to deliver dependable information serving users with widely differing needs and understanding, and to deliver actionable knowledge to subsistence farmers in particular.

This freely available resource brings together over 10,000 factsheets covering more than 6500 host plants and pests in over 80 languages. Factsheets include Pest Management Decision Guides and Plantwise Factsheets for Farmers, produced as part of the programme. Creating a format for pest management advice that is of practical use to smallholder farmers is a major challenge (Katherine et al. 2016; Chundi 2014; Masuki et al. 2011; Sones et al. 2015); therefore, CABI and its partners use models for pest management content that are easy to understand, containing effective, safe and practical advice for the local context. Plantwise Factsheets for Farmers (Bentley and Boa 2013) and Pest Management Decision Guides (Chernoh and Kuhlmann 2015) are developed in partnership with local experts. The materials are written in local languages and provide a range of IPM options, illustrated with images of pests to aid diagnosis. Plantwise Factsheets are reviewed by local farmers in the countries where they are written to ensure that the information 
is easy to understand and practical to use. They are validated by technical reviewers to check that the recommendations are safe and follow sound scientific principles. The Plantwise Knowledge Bank website, which has received over 2 million cumulative visits to date, provides diagnostic resources, best practice pest management advice and plant clinic data analysis for targeted crop protection (Leach and Hobbs 2013; Katherine et al. 2016).

The Country Resources section of the website contains country-specific resources including pesticide lists, diagnostic support and guidelines for writing extension materials. It is in this section that visitors will find the Plantwise Diagnostic Field Guide, which supplements training modules 1 and 2 on 'How to become a Plant Doctor' (Taylor 2015) (https://www.plantwise.org/diagnostic-field-guide/). The guide provides images and descriptions of many typical symptoms as well as 'ready reckoners', which are simple information tables for quick and easy reference, describing relationships between common symptoms on plants and the various possible causes. The guide also provides a short overview of the important principles for giving good advice, which are underpinned by an IPM approach.

\section{Plantwise Online Management System}

While the Plantwise Knowledge Bank is referred to as 'open access', the Plantwise Online Management System (POMS) is often referred to as the 'closed access' section of the Knowledge Bank. The POMS is a secure, bespoke, central data management system owned and maintained by CABI for managing plant clinic and administrative data necessary for the maintenance and analysis of clean information. Data contained within the POMS is only accessible via a username and password, and is owned by the country of origin.

When the plant clinics were first piloted under the Global Plant Clinic initiative, advisers began recording some basic information about the farmers who visited the clinics, their crops and problems, and the advice being given (Bentley 2009). The potential value of the data was recognised and CABI subsequently worked with partners to standardise data collection in each of the countries where Plantwise was operating.

\section{Plant Clinic Data Collection}

The interaction between a plant doctor and a farmer at a plant clinic is recorded on a prescription form, which is available as paper or electronically in a Data Collection application (DCA), for use on a phone or tablet. The record of each interaction is referred to as a clinic query. Those clinics operating with the electronic version of the prescription form are referred to as e-plant clinics. Information collected on 
paper forms is digitised using a desktop version of the DCA and all clinic queries, irrespective of form type, are collated in the POMS.

The prescription form takes a plant doctor through an 'interview' with a farmer, using the principles of IPM, to diagnose plant health problems and provide a suitable and safe recommendation either on a paper copy of the form or via a short message service (SMS) message sent directly to the farmer's phone. In e-plant clinics, a plant doctor is unlikely to have internet connection during clinic sessions; therefore, the DCA works offline for forms to be filled in and saved. When the plant doctor has sufficient internet coverage and/or mobile data, the forms can be submitted to the POMS. The app allows plant doctors to send SMS messages containing high quality advice to farmers, while quickly and easily collecting plant health data on crop grown, problem description, diagnosis and recommendation, during their regular clinics and farm visits. The app also includes a report feature so that plant doctors can keep track of how many farmers they have helped. This function enables them to see trends in country data and to quickly and easily update their supervisors on the number of farmers they have reached.

Plantwise tested the use of ICT (tablets and SMS) with 60 Kenyan extension workers during a 1-year pilot. Results indicated that extension workers were able to assist more farmers with better advice, had significantly improved access to plant health information, valued being able to ask their peers for advice, and dramatically improved the quality and speed of the data they collected (Wright et al. 2016). To date, over 3,953 plant doctors have been trained on the use of tablet computers at plant clinics in 28 countries.

The speed with which data are collected and the opportunities this creates for informing plant health services of current issues on the ground make e-plant clinics the preferred method of clinic service delivery.

Plant clinics operate in varied country contexts, but the Plantwise programme encourages the following operational guidelines to ensure that farmers' interests remain at the heart of service delivery:

- Plant clinics should accept any crop and any type of problem;

- Plant clinics should be open to all farmers and aim to provide equal access to men and women from all social and ethnic groups;

- Plant clinics should operate in a visible and accessible location, ideally somewhere that farmers go regularly, to minimise the effort and cost of facilitating an opportunity for face-to-face dialogue;

- Plant clinics should operate on a regular, or at least predictable, basis and at times that are convenient to farmers. Many of the clinics that have been established through Plantwise only run periodically, such as for a few hours per week or even less frequently. The periodicity depends on the availability and priorities of the extension staff; thus, a certain amount of publicity is typically required to let farmers know of the next clinic session (Jenner et al. 2020).

Because clinics are inclusive and offer advice on any crop and type of problem, plant doctors need to have basic plant health knowledge. They can supplement this with information in the Plantwise Factsheets Library app (see Offline Plantwise 
Knowledge Bank); the DCA was built to work well in combination with this app. Users are encouraged to switch between the apps, when needed, and even copy suitable recommendations from factsheets in the library and paste into the recommendation field of the DCA, which is used to create the SMS message. The DCA offers the functionality to collect data on the recommendation in one language, for country-wide analyses once the prescription form has been submitted to the central database, while sending an SMS message to the farmer in the local language. Approximately 1100 SMS messages were sent over the past year.

The DCA, although free to download, will only work for plant doctors with registered accounts and requires a username and password to log in. There are now 728,850 plant clinic queries in the POMS in the central database, submitted from 28 countries since inception in 2015, with nearly $60 \%$ submitted via the DCA and desktop version of the DCA.

Clinic queries that are submitted to the POMS are owned by national partners; therefore, during the process of setting up Plantwise in a country, a representative of the National Implementing Organization is required to sign a Data Sharing Agreement, countersigned by a representative of CABI, which outlines the terms of agreement for holding and using the data. Agreements can either be open (allowing $\mathrm{CABI}$ to hold the data in the POMS and publish on the globally accessible platform of the Plantwise Knowledge Bank) or closed (allowing CABI to hold the data, but not publish it). The whole process of managing clinic queries (data) is referred to as data management, and country partners undergo training, created by $\mathrm{CABI}$, to understand the process and the importance of collecting and using data.

The National Data Manager (often in collaboration with the National Coordinator), who is responsible for activities relating to data management, determines who has access to the data from the country concerned. The National Data Manager adheres to Terms of Reference that state "Identified by the National Responsible Organization, and working closely with other Plantwise stakeholders, the National Data Manager (NDM) will have the remit for the collection, processing, storage, distribution and management of plant clinic data for a country. They will also, in collaboration with local partners, oversee the implementation of the data management processes according to the country-specific yearly plans of operation."

In order to unlock the potential value of the clinic data, a key goal of the Plantwise programme is to make the clinic data as easily accessible and reusable as possible, and therefore tools within the POMS to clean and analyse data have been developed. A harmonization tool allows users (usually NDMs) to clean data submitted by the plant doctors and develop country-specific libraries of terms for ease of management. Once clinic queries are harmonized and submitted to the live system of the POMS they are available for users to interrogate online and offline. Data interrogation is enabled using data visualisation tools in the POMS or by choosing one of five download options facilitating offline analysis in Excel or statistical packages such as R. Plantwise is committed to providing online and offline tools for accessing and using information, and has developed an offline version of the data analysis tool. Data visualisation tools allow users to identify common and unusual pest 
occurrences, spread of new pests and pest outbreaks. The system provides mechanisms to analyse plant clinic data for targeted crop protection. Data collected in the POMS act as a feedback mechanism to identify problems in the field and provide targeted advice to farmers, e.g. for mass extension campaigns, identification of topics for the development of relevant extension materials, etc. In this way, plant doctors will be armed with the most relevant resources to help farmers combat pest problems.

\section{Offline Plantwise Knowledge Bank}

\section{Plantwise Factsheets Library App}

Advances in ICT and the increased popularity and accessibility of apps created an opportunity to provide another mechanism for accessing high quality plant health information. The Plantwise Factsheets Library app, launched in 2014, enables free, easy access to the most up-to-date, relevant material with the safest advice in the form of Plantwise Factsheets for Farmers and Pest Management Decision Guides. Plant doctors with mobile phones or tablets have thousands of factsheets at their fingertips when conducting plant clinic sessions, avoiding the need to carry books and leaflets, which could quickly become outdated. Users can download countryspecific factsheet packs when they have an internet connection and view those country packs offline, during remote clinic sessions. The app will periodically check the servers for updates to factsheets, enabling users to stay informed about what experts consider to be today's safest and most effective management techniques. The aim is that all main problems brought to the clinics will be covered by a relevant factsheet and that, by analysing clinic data, gaps in extension materials can be identified and filled (Katherine et al. 2016). The app has proved to be a success, with more than 15,000 users in over 150 countries viewing the app in more than 700,000 sessions to date; $95 \%$ of the usage is from countries where Plantwise operates.

\section{Plantwise Knowledge Bank USB Card}

Continuing the commitment of the Plantwise programme to deliver high quality actionable plant health information to online and offline users, the Plantwise Knowledge Bank USB card was also piloted in 2014, in several languages. It was found to be a valuable tool, especially in data validation sessions. It was developed as an offline version of the Plantwise Factsheets Library app. We developed and circulated a finite number of the USB cards in 2014, but no further batches were circulated and none of the ones in circulation have been updated since. In order for them to remain useful we would need a mechanism by which users could obtain updates easily (as with the Factsheet app). 


\section{Capacity Building for Diagnostics}

\section{Extension Service Providers}

The Plantwise programme is committed to leveraging ICT to continue plant doctor training remotely, supporting plant doctors who have attended Plantwise training modules 1 and 2, and who would benefit from continued education. In 2018, CABI published an e-learning course called PestSmart E-learning Diagnostics, which is derived from Plantwise material. The PestSmart Diagnostics package focuses specifically on improving the skills and methodologies required for field-based diagnosis. It helps plant health practitioners and students to develop and improve their ability to recognise symptoms, relate them to causes, and identify what is causing the problem. Containing high-resolution images, case studies and knowledge checks, the resource helps users improve their knowledge through practical, independent learning. The package covers the main pathogen groups as well as insect pests and nutrient deficiencies.

The PestSmart E-learning Diagnostics course and the PestSmart Diagnostic Simulator, together with the Diagnostic Field Guide, make up the PestSmart Diagnostics package. The aim of the package is to fast-track the field experience of plant health professionals and students by giving them CABI's wealth of field experience in a single course.

The PestSmart Diagnostic Simulator is one of several 'serious games' that have been launched and tested as a part of the Plantwise strategy to build the capacity of in-country partners to identify and diagnose pests, and to complement conventional training offered in other Plantwise training modules. The game is available on Google Play and has been developed in four languages: French, Spanish, Swahili and Chinese. Registered plant doctors and PestSmart users test their plant pest and disease investigation and diagnosis skills through seven novice-level scenarios. The game supports and reinforces the investigation and diagnosis skills of users through engaging gameplay and real-time feedback. It utilises simulated observation, inspection and deductive reasoning skills, combined with prior plant protection knowledge, to build confidence and competence in plant pest and disease diagnosis.

Another game, the Crop Management Simulator, encourages the player - in the role of a farm advisor - to help farmers face challenges of losing up to $40 \%$ of their crops to pests and diseases, based on the principles of IPM. In this game, strategies must be developed to prevent pests and diseases from destroying a farmer's crops. A range of problems from insects and mites to fungi, bacteria and viruses need to be defeated using an arsenal of control methods. Users can choose from a range of cultural, physical, biological and chemical control methods to combat pests and diseases. All control methods have their strengths and weaknesses, and can interact with each other in helpful or harmful ways. The characteristics of hundreds of pests and diseases on many globally important crops are accurate and realistic. Seasonal timing of pest attacks is modelled on real data. Changing weather patterns help to make the challenge realistic. 
Serious games have been shown to improve the learning capacity of players (Connolly et al. 2012; Vlachopoulos and Makri 2017) and the Android-based games created under the Plantwise programme help to ensure continuous engagement of users in a simulation of realistic working environments in plant clinics. The games contain realistic 3D models and scenarios so that plant doctors and extension workers can hone their diagnostic skills. Further study is required of the reliability and validity of the tool; learning effects of the simulation have not yet been conclusively investigated (Thompson et al. 2016).

Rapid and accurate identification of organisms is crucial to many research and applied outcomes. Diagnosis is a critical first step in determining the significance of suspected biosecurity threats posed by emergency plant pests (EPPs) and other invasive pests and pathogens (Thompson et al. 2011). Plant doctors are generally equipped with hand-held microscopes. USB microscopes, also known as computer microscopes or computer-connected microscopes, have been trialled in plant clinics in India. The hand-held microscopes can be plugged into a USB port on a computer or television, enabling users to examine specimens via a computer monitor or television screen. The macro lens of the USB computer microscope can touch an object to magnify it or it can be used to view objects at a short distance. The images can be saved as picture files or video films, printed and sent to diagnostic experts. Plant doctors use the technology when they are unable to diagnose a problem, and share pictures and videos with other plant doctors and experts. In India, these microscopes were found to attract more farmers, increasing plant clinic attendance, and increase the diagnostic ability of plant doctors (Thakur et al. 2016).

\section{Farmers}

Plant doctors and extension workers are important providers of agricultural information and advisory services; however, they face challenges in reaching farmers at scale due to their relatively small group size, difficulties in reaching remote farms, and low motivation and accountability (Anderson and Feder 2007; Bell 2015). ICTbased extension methods can enable broader and timely outreach to farmers, often in a cost-effective and interactive way (Saravanan et al. 2015; Toepfer et al. 2019). For example, Tambo et al. (2019) reported that participation in ICT-based extension campaigns significantly increases maize farmers' knowledge about fall armyworm and stimulates adoption of agricultural technologies and practices for its management in western Uganda. They reported that of three ICT channels tested - interactive radio, mobile SMS messages and village-based video screenings - radio has greater reach, video exerts a stronger impact on the outcome measures, and greater gains are achieved when video is complemented by radio. Exposure to multiple campaign channels yields significantly higher outcomes than exposure to a single channel. The authors concluded that complementary ICT-based extension campaigns (particularly those that allow both verbal and visual communication) hold great potential to improve farmers' knowledge and trigger behavioural changes in 
the identification, monitoring and sustainable management of a new invasive pest, such as fall armyworm.

\section{Plant Clinic Data Use}

Information exchange is at the heart of Plantwise, empowering plant doctors to advise farmers on growing healthy crops using the latest plant health information, while gaining insights into what problems farmers face to facilitate rapid responses. Plantwise priorities in 2019 include improvement of clinic data use by CABI and its partners. Countries in which Plantwise operates, where it is believed there is a good relationship with a range of stakeholders and where it is expected there may be greatest benefits from improving clinic data sharing, have been identified to engage in those discussions. CABI proposes to explore, with national data custodians and partners, options for mapping pest distribution, mapping and monitoring crops grown and identifying alternatives, monitoring pesticide (or other input) recommendations, monitoring service quality and 'certification', etc. Various stakeholders, including regulators, quarantine officers, agro-input manufacturers, policy makers and farmers can benefit from access to analyses of the data. Partners are already using clinic data to: assess which pests and crops are frequently brought to the clinics (Jayasundara et al. 2016); prioritise topics for development of new Pest Management Decision Guides; monitor the quality of diagnoses and advice (Danielsen et al. 2013); determine if gender affects the practicality of advice (Lamontagne-Godwin et al. 2016); assess which pesticides are being recommended and provide further training to reduce hazardous pesticide use; and monitor how male and female farmers are being reached through the plant clinics (Alokit et al. 2014).

While data sharing via the POMS requires a username and password, country partners also share data in open forums amongst groups of plant doctors, to monitor clinic activities and validate diagnoses and recommendations. Plantwise is providing forums for discussions on data sharing and use, aiming to facilitate interviews and group discussions, focused on enabling stakeholders to identify opportunities for sharing plant clinic data. Through its work with the Bill and Melinda Gates Foundation (BMGF), CABI has developed tools and models that are being used to map the data ecosystems of target countries, to identify challenges to and incentives for sharing. In each case we recommend next steps and draft national roadmaps for sharing of clinic data with defined audiences.

A number of challenges in managing the data before it can be used effectively were documented by Finegold et al. (2014). After trialling end-to-end data management in a number of countries, it was found that many of the logistic and quality challenges might be overcome by the introduction of ICT to the recording process. This led to piloting tablets in Kenya by plant doctors for recording data and communicating with others in the plant health system (Wright et al. 2016). 
Data quality presents a challenge to sharing and using information, and local partners are encouraged to carry out monitoring and quality assurance of the plant clinic data. Data validation includes assessing the quality of a diagnosis and recommendation based on the description captured by the plant doctor on the prescription form (Danielsen et al. 2013). This process is very time consuming, yet it provides valuable insights into the diagnostic strengths and weaknesses of extension staff. An offline tool for validating plant clinic data, used by National Data Validation teams, and data visualisation tools for validated data, are available in the POMS. CABI, through the Plantwise programme, is exploring options to build tools to automate validation, for example to trigger feedback to a plant doctor based on the diagnosis or recommendation that was made.

\section{Responding to Changing Plant Health Problems}

Plantwise is committed to the development of tools and processes for assisting rapid response to changing plant health problems encountered by smallholder farmers. A checklist of how to respond to emerging pests was developed for the Plantwise programme and is also used in the Action on Invasives programme, led by CABI.

A number of activities that are already part of the programme can be put into action rapidly in response to emerging threats. For example, a response within 1-2 days should comprise:

- writing an article for the Plantwise Blog based on news from websites, to include relevant information from the Plantwise Knowledge Bank, for example a PDF pack of factsheets about the pest;

- notifying the relevant people and sending them information from the Plantwise Knowledge Bank; for example, contacting CABI Country Coordinators in affected countries to let them know what information is available on a pest outbreak;

- ensuring that there are images in CABI's image management system, tagged so they appear on the Plantwise Knowledge Bank.

There are other activities that should take place within 1-2 weeks:

- finding useful and informative external factsheets by checking known sources and searching on the internet; if a useful factsheet is found it can be indexed as a priority for loading into the Plantwise Knowledge Bank;

- alerting the affected countries about the pest through Telegram; informing them how to recognise it and any advice on management; making sure this message has been validated by CABI scientists before sending if it is not clear what the advice should be;

- extracting POMS records that might be the pest; having images submitted with the clinic records reviewed by CABI scientists to see if they might be of the same species so that national partners can be alerted to investigate further; 
- updating distribution data for all online CABI products; ensuring that the National Plant Protection Organisation (NPPO) has signed it off if the pest is new to the country.

There are other activities that should take place within 1-2.5 months:

- ensuring coverage on the Plantwise Knowledge Bank, detailing host plant affected, symptoms, prevention and management information;

- creating global crop-specific Green Lists, predecessors to Pest Management Decision Guides, to enable quick dissemination of information as a basis for developing more detailed factsheets;

- commissioning Pest Management Decision Guides and/or Factsheets for Farmers in the countries affected, compiled by specialists and translated into local languages.

\section{Social Media Platforms}

The plant clinic network can benefit from development of social network groups on messenger apps (e.g. Telegram, WhatsApp, Line, Viber), which allows plant doctors to share problems amongst themselves and with local diagnostic experts.

Originally, plant doctors trained to use the DCA were set up in groups on Telegram, to encourage sustainability within the programme, and to provide backup for new users. This social media platform facilitated rapid exchange of information, not only for troubleshooting but also for sharing experience of pest outbreaks and management options (Thakur et al. 2018). Telegram has been used to share policy documents, agronomic resources, meteorological data and even to run lectures on plant health. Members of the Telegram groups reference Plantwise content, and also offer innovative management techniques using household items. Diagnosis may also be facilitated by sharing images of damaged plants with network members, and potentially with CABI's Diagnostic and Advisory Service staff who provide a diagnostic service for fungal and bacterial pathogens, nematodes, viruses, phytoplasmas and insects.

The detection of maize lethal necrosis disease (MLND) in Uganda illustrates how such techniques can be leveraged to quickly combat pest invasions. ICTs were used to initiate a rapid response to an issue in the Tororo district. An Agricultural Extension Officer, unable to diagnose the problem in a maize crop, shared images with the District Agricultural Officer the next day. After a telephone conversation, the Uganda District Agricultural Officer, who had attended a MLND sensitisation workshop held by the National Agricultural Research Organization and the Ministry of Agriculture, diagnosed MLND. It took only 3 days for the Agricultural Extension Officer to return to the farmer with management options. This is in direct contrast to events in Busia district where a more traditional approach of report writing and field visits culminated in a delay of 2 weeks between plant sample collection and confirmation that the problem was MLND (Bundi et al. unpublished). 
During the first pilot of ICTs in Plantwise, Kenya was battling with the tomato leafminer, Tuta absoluta. Data on this invasive insect was available in the POMS, 65 days earlier when collected on tablets rather than through paper documents. Plant doctors were seen to give higher quality recommendations using the dynamic materials on their tablets, through the Plantwise Factsheets Library app (Wright et al. 2016).

\section{Collaboration with Other Digital Initiatives}

Plantwise encourages collaboration with other programmes concerned with global food security. For example, in collaboration with Pestpoint (www.pestpoint.org.au), a digital platform offering advice from peers and experts on evidence-based pest identification, plant doctors in Myanmar, Vietnam and Thailand were provided with a tablet giving access to plant health information, with a magnifier that presented enlarged images of pest problems. The images were reported to facilitate detection and identification of a pest, with the opportunity to share on the Pestpoint platform and seek advice. An external study of the impact of plant clinic data management in the Plantwise programme reported that plant doctors involved in both programmes made use of the Pestpoint tools to support Plantwise-related activities and considered them complementary to their overall work as Agricultural Extension Officers (Sluijs and Posthumus 2017).

The International Food Policy Research Institute (IFPRI) has collaborated with Plantwise in scaling-up the "Seeing is believing" project activities under a CGIAR (Consortium for International Agricultural Research Centers) BigData Inspire Challenge grant. The project aims to help farmers in Tamil Nadu, India, using photographs taken with their own smartphones, to optimise agronomic decision-making for their crops. The project uses Plantwise plant doctors, plant clinics and partnerships for testing research interventions. A plant doctor's role is to promote the importance of picture-based advisories among farmers and to train them in taking photographs using IFPRI's WheatCam app. The Plantwise Knowledge Bank is used as a resource to create pest-based advice (McDade 2019).

PEAT, a German-based company, has developed an app, Plantix (https://plantix. net/en/), for identifying and managing plant health problems in the field. The app includes a community feature in which agricultural stakeholders can share knowledge. Plantix has collaborated with Plantwise in India to evaluate and improve the detection rate of Plantix, with emphasis on control options focussed on the principles of IPM, including biological-based pest management. The pilot uses a network of plant doctors to evaluate and improve the Plantix app. The app uses the smartphone's camera in delivering diagnosis of pests, diseases and nutrient deficiencies based on image recognition. Working as part of the wider Plantwise plant clinic network, and using data gained from the Plantwise Knowledge Bank, Plantix serves as a valuable tool in offering effective pest management advice. 


\section{Conclusions}

The title of this chapter is "Plantwise: a knowledge and intelligence tool for food security through crop protection". We have shown how Plantwise is both (1) a knowledge tool, that can extend guidance to farmers to help them manage pests and diseases on their crops, and (2) an intelligence tool, that can gather local news about those that are currently causing concern. This two-way flow of data - a distinguishing characteristic of Plantwise - is enabled through its deployment by plant doctors, especially in the context of plant clinics. A key element of such a tool is a dynamic, authoritative database.

These characteristics of Plantwise reflect those of the programme's leader, $\mathrm{CABI}$ - an international, not-for-profit organization that provides information and applies scientific expertise to solve problems in agriculture and the environment. By sharing science-based knowledge about crop health, through Plantwise and other projects, CABI helps smallholder farmers to grow more and lose less of what they produce, increase their incomes and improve their livelihoods.

As Plantwise operations have progressed since the programme's inception in 2011, new technology has transformed the way pests are reported and managed. Recent projects to develop and future-proof the open and closed platforms at the heart of the programme - the Plantwise Knowledge Bank and the Plantwise Online Management System - have focussed on mobile responsiveness, reflecting the huge increase in access to mobile devices. Emerging activities on social networks, supporting identification, monitoring and management of pests, are just one example of how technology has facilitated rapid information exchange.

Despite advances in technology, the implementation of Plantwise since the first pilot in 2014 has faced many challenges. These include limited digital literacy of plant doctors and farmers, poor enabling infrastructure in the countries, poor network connectivity, and insufficient budgets for providing the required infrastructure. During initial pilots, Plantwise contributed major funds towards creating an enabling environment, through distribution of tablets, internet access, and capacity building for plant doctors (Plantwise 2017). Varying levels of technical skills amongst plant doctors proved to be a major constraint (Wright et al. 2016). A case study of the DCA for plant health in Kenya showed that older plant doctors submitted more plant clinic records than their younger colleagues; and female plant doctors submitted more records than their male counterparts. Generally, plant doctors with higher standards of education, those with more experience, living in urban areas, and using Samsung tablets submitted more records than their less educated, less experienced counterparts, living in rural areas and using Lenovo tablets (Ochilo et al. 2019). Farmers without devices to receive SMS messages, together with poor literacy levels, also present major challenges to providing clinic services electronically. When farmers have phones, the devices are sometimes very basic and either the preferred language is not supported or the limit of the number of characters sent 
in one message is low. The handling of local languages during the digitization of data management in Plantwise has also been challenging (Wright et al. 2016; Thakur et al. 2016).

Over time, many countries have invested in purchasing their own tablets, and in some countries plant doctors are willing to use their personal devices. In most cases, Plantwise no longer provides airtime and in general, partners are willing to contribute to the sustainability of e-plant clinics because they see the benefits of ICTs and are keen to switch their clinic operations over to digital (Plantwise 2017).

Plantwise continues to foster new and existing collaborations to ensure the sustainability of the programme in countries where activities have progressed and adapted to opportunities to harness innovation and to promote streamlining and longevity of Plantwise activities. The increasing body of data lends itself to opportunities arising from CABI's role in hosting the Secretariat for the Global Open Data for Agriculture and Nutrition (GODAN) initiative from 2015 to 2019, and the process of linking data sets and working with 'big data'. GODAN is a call to action for better data to drive innovation and economic growth and to feed a growing global population. $\mathrm{CABI}$ is preparing to become a leading voice in the global Open Data movement and to catalyse innovative uses of data, for example in the Pest Risk Information Service (PRISE) project. PRISE, the largest technical project to emerge from Plantwise, was launched in 2016 and is funded by the UK Space Agency, linked to the Plantwise programme, and involves a consortium of partners from the UK and countries in sub-Saharan Africa. The project combines novel earth observation technology, satellite positioning, plant health modelling and on-the-ground real-time observations to deliver a science-based information service to predict pest outbreaks.

The implementation of Plantwise has developed into a fusion of ICT and nonICT approaches, working closely with country partners to maintain information flow and address food security issues of smallholder farmers, using the most suitable delivery techniques for country-specific contexts. New opportunities are focussed on enhancing pest monitoring, reporting and management, together with recognition of lessons learnt in implementing a complex programme spanning many developing countries and opportunities for advancement in new technologies.

Acknowledgements This Open Access book chapter has been made possible within the Plantwise programme, supported by contributions from the UK Foreign, Commonwealth and Development Office (FCDO), the Swiss Agency for Development and Cooperation (SDC), the Directorate General for International Cooperation (DGIS, Netherlands), the International Fund for Agricultural Development (IFAD), the Australian Centre for International Agricultural Research (ACIAR), and the Ministry of Agriculture and Rural Affairs of the People's Republic of China. 


\section{References}

Alokit, C., Tukahirwa, B., Oruka, D., Okotel, M., Bukenya, C., \& Mulema, J. (2014). Reaching out to farmers with plant health clinics in Uganda. Uganda Journal of Agricultural Sciences, $15(1), 15-26$.

Anderson, J. R., \& Feder, G. (2007). Agricultural extension. In R. Evenson \& P. Pingali (Eds.), Handbook of Agricultural Economics (Vol. 3, pp. 2343-2378).

Bell, M. (2015). ICT - Powering behavior change for a brighter agricultural future. Washington, DC: USAID/modernizing extension and advisory services (MEAS).

Bentley, J. W. (2009). Plant health clinics in Bolivia 2000-2009: Operations and preliminary results. Food Security, 1(3), 371-386.

Bentley, J., \& Boa, E. (2013). The snowman outline: Fact sheets by extensionists for farmers. Development in Practice, 23(3), 440-448.

Boa, E. (2009). How the global plant clinic began. Outlooks on pest management., 20(3), 112-116.

Bundi, M., Oronje, M. L., Romney, D., \& Hunt, S. (unpublished). Innovative use of ICT in early detection and rapid response of crop pests as a component of advisory service delivery.

Chernoh, E., \& Kuhlmann, U. (2015). The IOBC green and yellow list approach goes global with Plantwise. IOBC-Global Newsletter, 98(6).

Chundi, S. (2014). Driving effectiveness of last mile delivery in extension. Indian Journal of Fertilizers, 10(9), 104-107.

Connolly, T. M., Boyle, E. A., MacArthur, E., Hainey, T., \& Boyle, J. M. (2012). A systematic literature review of the empirical evidence on computer games and serious games. Computers \& Education, 59(2), 661-686.

Danielsen, S., Boa, E., Mafabi, M., Mutebi, E., Reeder, R., Kabeere, F., \& Karyeija, R. (2013). Using plant clinic registers to assess the quality of diagnoses and advice given to farmers: A case study from Uganda. The Journal of Agricultural Education and Extension, 19(2), 183-201. https://doi.org/10.1080/1389224X.2012.741528.

FAO. (2013). Glossary of phytosanitary terms (International standard for phytosanitary measures 5). Rome: FAO.

Finegold, C., Oronje, M., Leach, M. C., Karanja, T., Chege, F., \& Hobbs, S. L. A. (2014). Plantwise Knowledge Bank: Building sustainable data and information processes to support plant clinics in Kenya. Agricultural Information Worldwide, 6, 96-101.

International Fund for Agricultural Development. (2013). Smallholders, food security and the environment. Rome: United National Environment Programme.

Jayasundara, M. U. P., Herath, Y. M. C. K., Abeykoon, A. N., \& Cameron, K. (2016). The "Permanent Crop Clinic Programme" in Sri Lanka: making use of data to resolve crop health problems. Poster presented at Annual Symposium of Department of Agriculture 2016, Sri Lanka.

Jenner, W., Cameron, K., Reeder, R. (2020). Emerging Plant Diseases and Global Food Security. Section III: Dtection, Modeling and Evolution. Chapter 10: Plantwise: Monitoring PLant Pest Outbreaks Globally, 201-220. The American Phytopathological Society.

Katherine, H. C., Somachandra, K. P., Curry, C. N., Jenner, W. H., \& Hobbs, S. L. A. (2016). Delivering actionable plant health knowledge to smallholder farmers through the Plantwise program. Journal of Agricultural \& Food Information, 17(4), 212-229.

Lamontagne-Godwin, J., Williams, F., Bandara, W. M. P. T., \& Appriah-Kubi, Z. (2016). Quality of extension advice: A gendered case study from Ghana and Sri Lanka. Journal of Agricultural Education and Extension. https://doi.org/10.1080/1389224X.2016.1230069.

Leach, M. C., \& Hobbs, S. (2013). Plantwise knowledge bank: Delivering plant health information to developing country users. Learned Publishing, 26(3), 180-185. https://doi. org/10.1087/20130305. 
Masuki, K. F. G., Mowo, G. J., Kmugisha, R. N., Opondo, C. J., \& Tanui, J. K. (2011). Improving smallholder farmers' access to information for enhanced decision making in natural resource management: Experiences from southwestern Uganda. In A. Bationo, B. Waswa, J. M. Okeyo, F. Maina, \& J. M. Kihara (Eds.), Innovations as key to the Green Revolution in Africa: Exploring the scientific facts (pp. 1145-1160). Dordrecht: Springer. https://doi. org/10.1007/978-90-481-2543-2_117.

McDade, M. (2019). Retrieved from https://bigdata.cgiar.org/blog-post/seeing-really-is-believingwhen-farmers-photos-revolutionize-insurance-and-advisory-services/

Ochilo, W. N., et al. (2019). Can you ensure that ICT for development apps are downloaded and used? A case study of the plantwise data collection app for plant health in Kenya. Journal of Agricultural and Food Information. https://doi.org/10.1080/10496505.2019.1609967.

Oerke, E. C. (2006). Crop losses to pests. Journal of Agricultural Science, 144(1), 31-43.

Pestpoint website: https://www.pestpoint.org.au. Accessed 26 Sept 2019.

Plantix website: https://plantix.net/en/. Accessed 26 Sept 2019.

Plantwise website: https://www.plantwise.org/. Accessed 30 Sept 2019.

Plantwise. (2017). Plantwise annual report. Retrieved from https://www.plantwise.org/wpcontent/uploads/sites/4/2019/03/Plantwise-Annual-Report-2017.pdf

Saravanan, R., Sulaiman, R. V., Davis, K., \& Suchiradipta, B. (2015). Navigating ICTs for extension and advisory services. Note 11. GFRAS good practice notes for extension and advisory services. Lindau: GFRAS.

Savary, S., Willocquet, L., Pethybridge, S. J., et al. (2019). The global burden of pathogens and pests on major food crops. Nature Ecology and Evolution, 3, 430-439. https://doi.org/10.1038/ s41559-018-0793-y.

Sluijs, J., \& Posthumus, H. (2017). An assessment of the use, management and functioning of the Myanmar Plantwise Data Management System. Plant clinic data management Report. Retrieved from: https://www.plantwise.org/wp-content/uploads/sites/4/2019/03/Sluijs-AndPosthumus-Data-Management-System-Myanmar-2017.pdf

Sones, K. R., Oduor, G. I., Watiti, J. W., \& Romney, D. (2015). Communicating with smallholder farming families-a review with a focus on agro-dealers and youth as intermediaries in subSaharan Africa. CAB Reviews, 10(30), 1-6.

Sustainable Development Goals. (2017). Available online: https://sustainabledevelopment.un.org/ sdgs. Accessed 27 Sept 2019.

Tambo, J. A., Aliamo, C., Davis, T., Mugambi, I., Romney, D., Onyango, D. O., Kansiime, M., Alokit, C., \& Byantwale, S. T. (2019). The impact of ICT-enables extension campaign on farmers' knowledge and management of fall armyworm in Uganda. PLoS One. https://doi. org/10.1371/journal.pone.0220844.

Taylor, P. (Ed.). (2015). Plantwise diagnostic field guide. Wallingford: CABI.

Thakur, M., Pandit, V., Chaudhary, M., \& Rajikumar, R. (2016). ICT interventions in crop health knowledge management for smallholder farmers. Journal of Global Communication, 9, 35-46.

Thakur, M., Pandit, V., Rehman, A., Cameron, K. H., \& Beverley, C. (2018). Leveraging information and communication technologies for strengthening plant health extension services in South Asia. In L. N. A. Chandana Jayawardena, M. Suryamani, \& C. Sivayoganathan (Eds) Extnicon 2018: Transforming agricultural extension systems: Towards achieving the relevant Sustainable Development Goals (SDGs) for Global Impact, 10-12 May 2018, Kandy, Sri Lanka, Sri Lanka Agricultural Extension Association, Sri Lanka, pp. 201-208.

Thompson, M. F., Lyons, A., Kumarasinghe, L., Peck, D. R., Kong, G., Shattuck, S., \& La Salle, J. (2011). Remote microscopy: A success story in Australian and New Zealand plant biosecurity. Australian Journal of Entomology, 50, 1-6.

Thompson, M., Taylor, P., Reeder, R., Kuhlmann, U., Nolan, C., Mason, J., \& Hall, J. (2016). Exploring the value of simulations in plant health in the developing world. In T. Marsh, M. Ma, 
M. F. Oliveira, J. B. Baalsrud Hauge, \& S. Göbel (Eds.), Serious games. Proceedings, second joint international conference, JCSG 2016, Brisbane, QLD, Australia, September 26-27, 2016 (Lecture notes in computer science 9894) (pp. 153-162). Cham: Springer.

Toepfer, S., Kuhlmann, U., Kansiime, M., Onyango, D. O., Davis, T., Cameron, K., \& Day, R. (2019). Communication, information sharing, and advisory services to raise awareness for fall armyworm detection and area wide management by farmers. Journal of Plant Diseases and Protection, 126, 103-106.

Vlachopoulos, D., \& Makri, A. (2017). The effect of games and simulations on higher education: A systematic literature review. International Journal of Educational Technology in Higher Education, 14, 1-33.

Wright, H. J., Ochilo, W., Pearson, A., Finegold, C., Oronje, M., Wanjohi, J., Kamau, R., Holmes, T., \& Rumsey, A. (2016). Using ICT to strengthen agricultural extension systems for plant health. Journal of Agricultural \& Food Information. https://doi.org/10.1080/10496505.201 5.1120214 .

Open Access This chapter is licensed under the terms of the Creative Commons Attribution 4.0 International License (http://creativecommons.org/licenses/by/4.0/), which permits use, sharing, adaptation, distribution and reproduction in any medium or format, as long as you give appropriate credit to the original author(s) and the source, provide a link to the Creative Commons license and indicate if changes were made.

The images or other third party material in this chapter are included in the chapter's Creative Commons license, unless indicated otherwise in a credit line to the material. If material is not included in the chapter's Creative Commons license and your intended use is not permitted by statutory regulation or exceeds the permitted use, you will need to obtain permission directly from the copyright holder. 